\title{
Prevalence of Maternal Morbidity and Its Association with Socioeconomic Factors: A Population-based Survey of a City in Northeastern Brazil
}

\section{Prevalência da morbidade materna e sua associação com fatores socioeconômicos: estudo de base populacional em uma capital do nordeste brasileiro}

\author{
Tatyana Souza Rosendo ${ }^{1}$ Angelo Giuseppe Roncalli ${ }^{2}$ George Dantas de Azevedo ${ }^{3}$
}

\footnotetext{
${ }^{1}$ Departament of Collective Health, Universidade Federal do Rio Grande do Norte, Natal, RN, Brazil

2 Departament of Odontology, Programa de Pós-Graduação em Saúde Coletiva, Universidade Federal do Rio Grande do Norte, Natal, RN, Brazil

3 Escola Multicampi de Ciências Médicas do Rio Grande do Norte, Universidade Federal do Rio Grande do Norte, Natal, RN, Brazil
}

\begin{abstract}
Address for correspondence Tatyana Souza Rosendo, MD, Departamento de Saúde Coletiva, Universidade Federal do Rio Grande do Norte, Av. Senador Salgado Filho, 3.000-Lagoa Nova, 59078-970 Natal, RN, Brasil (e-mail: tatyana.ufrn@hotmail.com).
\end{abstract}

Rev Bras Ginecol Obstet 2017;39:587-595.

\begin{abstract}
Keywords

- maternal mortality

- morbidity

- pregnancy complications

- health surveys

- health care disparities
\end{abstract}

Purpose To identify the prevalence of maternal morbidity and its socioeconomic, demographic and health care associated factors in a city in Northeastern Brazil.

Methods A cross-sectional and population-based study was conducted, with a design based on multi-stage complex sampling. A validated questionnaire was applied to 848 women aged between 15 and 49 years identified in 8,227 households from 60 census tracts of Natal, the capital of the state of Rio Grande do Norte (RN), Brazil. The main outcome measure was maternal morbidity. The Poisson regression analysis, with $5 \%$ significance, was used for the analysis of the associated factors.

Results The prevalence of maternal morbidity was of $21.2 \%$. A bivariate analysis showed the following variables associated with an increased number of obstetric complications: non-white race (prevalence ratio $[\mathrm{PR}]=1.23 ; 95 \%$ confidence interval $[95 \% \mathrm{Cl}]: 1.04-1.46$ ); lower socioeconomic status ( $\mathrm{PR}=1.33 ; 95 \% \mathrm{Cl}$ : 1.12-1.58); prenatal care performed in public services ( $P R=1.42 ; 95 \% \mathrm{Cl}: 1.16-1.72)$ : women that were not advised during prenatal care about where they should deliver $(\mathrm{PR}=1.24$; $95 \% \mathrm{Cl}$ : $1.05-1.46)$; delivery in public services ( $P R=1.63 ; 95 \% \mathrm{Cl}: 1.30-2.03)$; need to search for more than one hospital for delivery ( $\mathrm{PR}=1.22 ; 95 \% \mathrm{Cl}$ : $1.03-1.45)$; and no companion at all times of delivery care ( $P R=1.25,95 \% \mathrm{Cl}: 1.05-1.48)$. The place where the delivery occurred (public or private) and the socioeconomic status remained significant in the final model.

Conclusion Women in a worse socioeconomic situation and whose delivery was performed in public services had a higher prevalence of maternal morbidity. Such an received

January 30, 2017

accepted

June 21, 2017

published online

August 23, 2017
DOI https://doi.org/

10.1055/s-0037-1606246. ISSN 0100-7203.
Copyright $(2017$ by Thieme Revinter

Publicações Ltda, Rio de Janeiro, Brazil
License terms

(ㄷ) (i) $\ominus$ (5) 


\section{Resumo}

\author{
Palavras-chave \\ - mortalidade \\ materna \\ - morbidade \\ - complicações na \\ gravidez \\ - estudos em saúde \\ - desigualdades em \\ saúde
}

association reinforces the need to strengthen public policies to tackle health inequalities through actions focusing on these determinants.

Objetivo Identificar a prevalência da morbidade materna e os fatores socioeconômicos, demográficos e de assistência à saúde associados a ela em uma capital do Nordeste brasileiro.

Métodos Estudo seccional, de base populacional, com desenho de amostras complexas. Aplicou-se um questionário validado para morbidade materna em 848 mulheres com idade entre 15 e 49 anos selecionadas em 8.227 domicílios distribuídos em 60 setores censitários de Natal, capital do Rio Grande do Norte, Brasil. O desfecho principal foi a morbidade materna. A análise multivariada foi feita por meio da regressão de Poisson, com 5\% de significância.

Resultados A prevalência de morbidade materna foi de 21,2\%. A análise bivariada encontrou associação entre o maior número de complicações obstétricas com: mulheres da raça preta/parda (razão de prevalência [RP] = 1,23; intervalo de confiança de 95\% [IC95\%]: 1,04-1,46); pior condição socioeconômica (RP =1,33; IC95\%: 1,12-1,58); pré-natal na rede pública ( $R P=1,42$; IC95\%: $1,16-1,72)$; mulheres que não foram informadas sobre o lugar da realização do parto durante o pré-natal $(\mathrm{RP}=1,24$; IC95\%: 1,05-1,46); mulheres que realizaram o parto na rede pública $(\mathrm{RP}=1,63$; IC95\%: 1,30-2,03); pacientes que percorreram mais de um hospital para realizar o parto ( $R P=1,22$; IC95\%: $1,03-1,45)$; e aquelas que não tiveram acompanhante em todos os momentos da assistência ao parto - antes, durante e depois do parto $(R P=1,25 ;$ IC95\% $=1,05-1,48)$. No modelo final da regressão, tanto o local do parto quanto a condição socioeconômica mantiveram a associação.

Conclusões A maior prevalência da morbidade materna esteve associada às piores condições socioeconômicas e à realização do parto na rede pública. Isso reforça a necessidade de fortalecimento de políticas públicas que reduzam as desigualdades em saúde.

\section{Introduction}

Social and economic policies promote a significant impact on how people are born, grow up, live and die. Furthermore, social inequalities can and must be addressed through public policies. Social development may be measured in different ways, such as through the quality of the health of the population, the possibility of offering health services to different social classes, also by the way health care services support the diseased population. Consequently, for rich and poor countries, health and disease are directly associated to socioeconomic status: the worse the status, the worse the quality of the health. ${ }^{1}$

Regarding women's health worldwide, indicators of mortality and morbidity have shown health inequalities, and are, therefore, good indicators of the human, social and economic development levels. They reveal inequalities regarding lack of education, low social and family support, absence of health resources, and those related to living in areas with social deprivation. 2,3

In spite of unfavorable maternal outcomes such as maternal death and severe maternal morbidity being related to social determinants, it is possible to reduce their prevalence, especially in developing countries. This may be achieved through a health care model that includes access to family planning and to obstetric assistance during prenatal care and delivery. ${ }^{3}$ Therefore, health care services play an important role in the reduction of maternal morbidity and mortality, and have great potential to reduce inequalities as well. This can even be true for the developed countries in which inequalities still persist, despite health indicators having improved. ${ }^{1,2,4}$

The study of maternal morbidity includes a range of conditions, from potentially life-threatening conditions to those more severe, also known as maternal near misses. Such studies have been strategic in reducing maternal mortality, as they increase the implementation of health care models based on both epidemiological surveillance and health care planning. Such studies can be useful to the evaluation of health service quality, for they contribute to the identification of priorities in intervention and investment. ${ }^{5}$

The assessment of the prevalence and the factors associated to severe maternal morbidity has been presented as an important strategy to improve maternal health. ${ }^{6}$ This applies especially to Brazil, which has shown significant progress in social and economic development in recent years, including the implementation of public policies that affect the social 
determinants of maternal mortality, such as the cash transfer programs. In addition, Brazil has not achieved the last steps of the obstetric transition, in which the maternal mortality is low or very low, and, hence, the indirect causes have a higher impact on the existing cases. ${ }^{7}$

Studies focusing on the prevalence and the factors associated to maternal morbidity are not rare, be it in developed or developing countries. Most of them are related to hospital auditing. The performance of population surveys has also been proposed as a feasible alternative to study this issue, especially in some regions where health information is still scarce and non-systematic. $^{8-14}$

Considering the importance of this matter and also the possibilities to improve maternal assistance, performing studies on this issue is necessary. Therefore, the present study aims to identify the socioeconomic, demographic and health carerelated factors associated to the prevalence of maternal morbidity in a state capital city in the Northeast region of Brazil.

\section{Methods}

\section{Study Design and Population}

A population-based cross-sectional study was performed in Natal, the capital city of the state of Rio Grande do Norte (RN), situated in the Northeast region of Brazil. The estimated population was $\sim 800,000$ inhabitants according to data collected in 2010. The inclusion criterion was being a woman of reproductive age (between 15 and 49 years old) who had been pregnant at least once in the previous 5 years. We used a questionnaire previously validated by Souza et $\mathrm{al}^{15}{ }^{15}$ who identified the clinical conditions and/or interventions mentioned by women that would be used as maternal complications markers in population-based studies. ${ }^{13}$ This questionnaire was structured in several close-ended questions and applied to the subjects by a trained interviewer. These questions were related to the identification of maternal morbidity, socioeconomic status, demographic characteristics and maternal assistance during the prenatal care and postpartum. A modification in this questionnaire was made by the inclusion of the condition "urinary tract infection," based on the importance that these infections have in pregnant women; if they are not properly treated, they can get worse and develop to pyelonephritis, which is responsible for more severe conditions, such as septicemia and respiratory failure. These conditions are also related to infant prematurity, according to some literature findings. ${ }^{16}$ As the inclusion of this condition has low capacity to substantially modify the indicator used, it was not necessary to validate it. Besides, the questionnaire contains other questions that enabled us to achieve more accuracy in the diagnosis of urinary infection.

The sample size was calculated based on another population-based study performed by Souza et al, ${ }^{13}$ whose results showed a $22 \%$ prevalence of maternal complications in Brazil. We applied an error rate of $15 \%$, and a 1.5 design effect to this estimate, resulting in a minimal sample size of 908 women. ${ }^{17}$ Finally, a 20\% non-response rate was applied, aiming to avoid sample loss, resulting in a final sample of 1,135 women of reproductive age. We accomplished a complex sample design with multiple stages. The primary sampling units (PSUs) were 60 census tracts in which the households were randomly selected.

The sample planning followed the recommendations for household-based research in developing countries, adapting the route technique in census tracts and blocks from the method recommended by the World Health Organization (WHO) for the Expanded Program on Immunization (EPI) Coverage Survey. ${ }^{18}$ The number of households was obtained from a proportion between the sample size $(1,135)$ and the household density ( 0.275$)$, which resulted in 4,128 residences. A pilot study was conducted to anticipate any difficulties in the data collection. Regarding the quality control of the field teams, we accomplished supervision in $10 \%$ of the census tracts during and after the data collection.

\section{Outcome Variables}

The prevalence of maternal morbidity was calculated by dividing the number of women that reported at least one maternal complication by the number of pregnancies in the previous five years. When a given woman informed that she had two or more pregnancies, only the last one was considered. Due to the fact that we have used maternal morbidity as an outcome, and not only the "maternal near miss," we decided to change the denominator, using the number of pregnancies occurred in the same period (previous five years), instead of the number of childbirths, as did Souza et $\mathrm{al}^{13}$ in their article. To identify the associated factors, we considered the number of maternal complications (numeric variable), since the same woman could have reported the occurrence of more than one complication.

\section{Independent Variables}

The explanatory variables were age, marital status, race (skin color), level of formal education, household income, possessions and household crowding (rate between the number of people living in the house and the number of bedrooms) and occupation (employed or unemployed). In order to reduce the number of independent variables, we performed a factor analysis including education, income and possessions, creating a single variable that represented the previous ones. This strategy was based on principal component analysis (PCA), and produced a single factor, named socioeconomic status (SES). In order to include this variable in the model of analysis, it was dichotomized from the median, turning into a string variable with two categories: high and low SES.

The variables related to maternal assistance during pregnancy, delivery and postpartum were, among others: performing prenatal care; number of prenatal care appointments; time of the first prenatal care appointment; type of health service where prenatal care was performed (public or private); referral to health services; basic exams recommended by the Ministry of Health; instructions on where the delivery would occur; delivery performed in the same place to which the patient was instructed to go; type of health service where the delivery was performed; delivery performed in the first hospital; type of delivery; companion before the delivery; companion during the delivery; companion after the delivery; companion full time; and days of hospitalization. 


\section{Statistical Procedures}

The prevalence of maternal complications was calculated taking into account the requirements for complex sample analysis, which means the inclusion of both sample weights and design effects in the prevalence estimates. In order to analyze the effect of the associated factors, we calculated the prevalence ratio (PR) adjusted for confounding variables using the Poisson regression model with robust variances, with a significance level of $5 \%$. The variables that presented a $p<0.20$ in the bivariate analysis were selected for multiple modeling. Two blocks of variables were considered in the modeling: SES and demographic characteristics, and those related to maternal assistance. In this procedure, we did not consider the sample weights and design effect, as they did not present a relevant effect on the confidence interval.

\section{Ethical Issues}

This research was approved by the Ethics in Research Committee of our institution under protocol number: 39057/12, and all persons gave their informed consent prior to their inclusion in the study.

\section{Results}

In the final sample, 848 eligible women (women of reproductive age who had at least one pregnancy in the previous five years) were interviewed in 8,227 households. Although 1,132 women had been effectively identified, the final sample was below the calculated minimal size, due to losses related to refusals to participate (65) and absence from home after 3 attempts to visit (219). As the calculated minimal sample size was 908 women, the response-rate was $93.4 \%$, corresponding to a loss of less than $7 \%$, which did not interfere on the precision of the estimates. It is plausible to affirm that the sample losses did not introduce a systematic bias and have, in this case, an irrelevant effect on the significance of the results.

The final number of women interviewed represents a sample with a prevalence rate of $21.2 \%$, with an error margin of $3.4 \%$. Considering the analysis of the associated factors, this sample has a power to detect a PR of up to 1.4. The flowchart in -Fig. 1 depicts how the sample was obtained.

- Table 1 shows a description of the sample according to some socioeconomic and demographic variables. The prevalence of severe maternal morbidity was of $4 \%$. The prevalence of maternal morbidity was of $21.2 \%$ (95\% confidence interval [95\%CI]: 18.3-24.5). Hemorrhage (10.7\%) and urinary tract infection $(10.7 \%)$ were the most frequently reported clinical conditions, and hospitalization for over a week after delivery was the most frequent intervention (5.4\%) (-Table 2). The non-adjusted analysis showed that the maternal complications were associated with women: who were non-white; with low SES; with prenatal care performed in a public service; who performed the basic exams recommended by the Ministry of Health; who received no instructions during the prenatal care about where the delivery would take place; who had the delivery performed in a public service; who did not have the delivery performed in the first hospital; who did

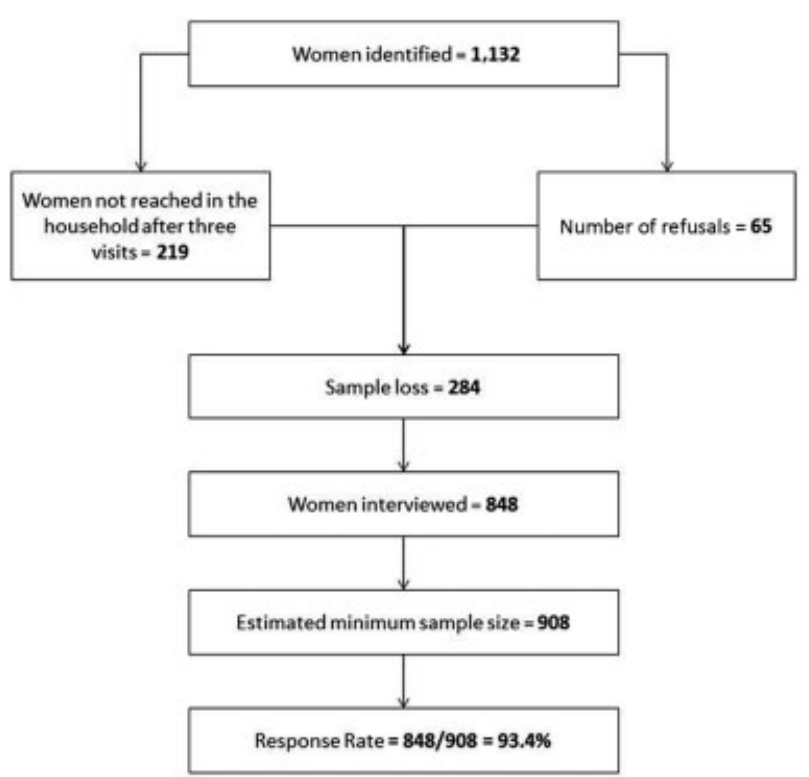

Fig. 1 Flowchart of the study sample.

Table 1 Sample description, according to the variables related to socioeconomic status, demographic characteristics and maternal assistance. Natal (RN), Brazil, 2014

\begin{tabular}{|c|c|c|c|c|}
\hline \multicolumn{2}{|l|}{ Variables } & \multirow{2}{*}{$\frac{n^{*}}{671}$} & \multirow{2}{*}{$\frac{\%^{* *}}{78.7}$} & \multirow{2}{*}{$\frac{95 \% \mathrm{Cl}^{* *}}{75.5-81.6}$} \\
\hline Age & $\begin{array}{l}\leq 34 \text { years } \\
\text { old }\end{array}$ & & & \\
\hline & $\begin{array}{l}\geq 35 \text { years } \\
\text { old }\end{array}$ & 174 & 21.3 & $18.4-24.5$ \\
\hline & Total & 845 & 100.0 & \\
\hline \multirow[t]{3}{*}{ Race (skin color) } & White & 286 & 34.7 & $30.1-39.7$ \\
\hline & Non-white & 525 & 65.3 & $60.3-69.9$ \\
\hline & Total & 811 & 100.0 & \\
\hline \multirow[t]{3}{*}{ Marital status } & $\begin{array}{l}\text { Married/ } \\
\text { stable } \\
\text { relationship }\end{array}$ & 539 & 68.7 & $61.8-74.9$ \\
\hline & $\begin{array}{l}\text { Single/ } \\
\text { divorced }\end{array}$ & 241 & 31.3 & $25.1-38.2$ \\
\hline & Total & 780 & 100.0 & \\
\hline \multirow{3}{*}{$\begin{array}{l}\text { Socioeconomic } \\
\text { Status }\end{array}$} & High & 343 & 51.7 & $44.0-59.3$ \\
\hline & Low & 342 & 48.3 & $40.7-56.0$ \\
\hline & Total & 685 & 100.0 & \\
\hline \multirow{3}{*}{$\begin{array}{l}\text { Type of health } \\
\text { service where } \\
\text { prenatal care } \\
\text { was performed }\end{array}$} & Private & 242 & 30.6 & $24.6-37.4$ \\
\hline & Public & 587 & 69.4 & $62.6-65.4$ \\
\hline & Total & 829 & 100.0 & \\
\hline \multirow{3}{*}{$\begin{array}{l}\text { Type of health } \\
\text { service where } \\
\text { delivery was } \\
\text { performed }\end{array}$} & Private & 162 & 24.1 & $18.3-31.0$ \\
\hline & Public & 559 & 75.9 & $69.0-81.7$ \\
\hline & Total & 721 & 100.0 & \\
\hline \multirow[t]{3}{*}{ Type of delivery } & Normal & 409 & 48.0 & $42.8-53.2$ \\
\hline & Cesarean & 428 & 52.0 & $46.8-57.2$ \\
\hline & Total & 837 & 100.0 & \\
\hline
\end{tabular}

Abbreviation: $95 \% \mathrm{Cl}, 95 \%$ confidence interval.

Notes: "sample size without weights and design effects; ** data calculated considering weights and design effects. Proportion calculated in relation to the amount of pregnancies, which is the same as the number of subjects (848). 
Table 2 Absolute and relative frequencies, with respective 95\% confidence intervals, of self-reported maternal complications. Natal (RN), Brazil, 2014

\begin{tabular}{|c|c|c|c|c|}
\hline \multicolumn{2}{|c|}{$\begin{array}{l}\text { Complications } \\
\text { (clinical conditions } \\
\text { or interventions) }\end{array}$} & \multirow{2}{*}{$\begin{array}{l}n^{*} \\
85\end{array}$} & \multirow{2}{*}{$\begin{array}{l}\%^{* *} \\
10.7\end{array}$} & \multirow{2}{*}{$\begin{array}{l}95 \% \mathrm{Cl}^{* *} \\
8.4-13.4\end{array}$} \\
\hline \multirow{9}{*}{$\begin{array}{l}\text { Clinical } \\
\text { conditions }\end{array}$} & Hemorrhage & & & \\
\hline & $\begin{array}{l}\text { Urinary tract } \\
\text { infection }\end{array}$ & 91 & 10.7 & $8.7-13.0$ \\
\hline & Septicemia & 44 & 5.2 & $3.8-7.1$ \\
\hline & Icterus & 37 & 4.5 & $3.1-6.3$ \\
\hline & $\begin{array}{l}\text { Pre-eclampsia/ } \\
\text { eclampsia }\end{array}$ & 34 & 4.3 & $2.9-6.2$ \\
\hline & $\begin{array}{l}\text { Chronic } \\
\text { hypertension }\end{array}$ & 26 & 2.8 & $1.6-4.8$ \\
\hline & Abortion & 11 & 1.6 & $0.9-2.7$ \\
\hline & Eclampsia & 10 & 1.3 & $0.7-2.3$ \\
\hline & $\begin{array}{l}\text { Gestational } \\
\text { diabetes }\end{array}$ & 6 & 0.8 & $0.3-1.8$ \\
\hline \multirow[t]{7}{*}{ Interventions } & $\begin{array}{l}\text { Hospitalization } \\
\text { for }>1 \text { week }\end{array}$ & 44 & 5.4 & $3.9-7.4$ \\
\hline & $\begin{array}{l}\text { Transfer } \\
\text { between } \\
\text { hospitals }\end{array}$ & 35 & 4.2 & $2.9-6.0$ \\
\hline & $\begin{array}{l}\text { ICU } \\
\text { hospitalization }\end{array}$ & 16 & 1.8 & $1.1-3.1$ \\
\hline & $\begin{array}{l}\text { Blood } \\
\text { transfusion }\end{array}$ & 10 & 1.2 & $0.6-2.3$ \\
\hline & Laparotomy & 11 & 1.1 & $0.5-2.2$ \\
\hline & $\begin{array}{l}\text { Mechanical } \\
\text { ventilation }\end{array}$ & 7 & 0.9 & $0.4-2.4$ \\
\hline & Hysterectomy & 2 & 0.2 & $0.1-0.9$ \\
\hline \multicolumn{2}{|c|}{$\begin{array}{l}\text { At least one of these } \\
\text { complications }\end{array}$} & 176 & 21.2 & $18.3-24.5$ \\
\hline
\end{tabular}

Abbreviation: $95 \% \mathrm{Cl}$, 95\% confidence interval; ICU, intensive care unit. Notes: *sample size without weights and design effects; ${ }^{* *}$ data calculated considering weights and design effects. Proportion calculated in relation to the amount of pregnancies, which is the same as the number of subjects (848).

not have a companion during delivery; and who did not have a companion full time. The number of days of postpartum hospitalization was higher in those women who had more complications (-Table $\mathbf{3}$ ).

Regarding the multiple analyses, age, race (skin color), marital status and SES were included, as they had $p<0.20$. Race and SES remained significant (PR: 1.23; 95\%CI: $1.03-$ 1.46). In the block of variables related to maternal assistance, only the type of health care service where the delivery occurred remained significant (PR: $1.51 ; 95 \% \mathrm{CI}$ : 1.21-1.87). Next, the regression modeling was performed with three variables: race, SES and location of delivery. Both delivery location (public or private services) and SES remained significant in the final model (-Table 4).

\section{Discussion}

The main finding of this research was the fact that those women in a worse socioeconomic situation had higher prevalence of maternal complications, irrespective of the type of health care service (public or private) where the delivery occurred. In addition, women whose delivery was performed in public services had more complications, irrespective of their socioeconomic status, since both variables remained in the final model, and showed a significant association with the occurrence of complications during pregnancy, delivery or the postpartum period.

Social determination in the maternal health context has been profoundly debated, and it is very important in relation to the most tragic outcomes, namely maternal deaths. ${ }^{19}$ Although the impact of social determination in the causal chain of events is weaker in relation to maternal morbidity and mortality, it is clear that poorer women are more likely to die from obstetric complications. ${ }^{2}$ However, public policies that improve the health care system and enhance the quality of assistance can attenuate the effects of social determinants, reducing inequalities.

In the present study, the prevalence rates of the complications related to pregnancy and the postpartum period were similar to those of other population-based studies with self-reported maternal morbidity. Souza et $\mathrm{al}^{11}$ found $18 \%$ of pregnancy complications, ranging from $15 \%$ to $22 \%$, depending on the region studied in Brazil. It is noteworthy that, in the aforementioned study, the authors used the number of childbirths in the denominator, which could limit the comparison with our study. Analyzing population surveys in countries from Latin America, Souza et $\mathrm{al}^{20}$ found a prevalence of $17 \%$ of pregnancy complications for Brazil. In another study, Souza et $\mathrm{al}^{13}$ also identified te prevalence of maternal morbidity using the same definition adopted in the present study, finding a prevalence of $22 \%$ for Brazil. More recently, Cecatti et $\mathrm{al}^{21}$ found $37.5 \%$ of pregnancy complications among women using the public health care system in the Amazon and Northeast regions of Brazil.

As in the study by Souza et al, $^{13}$ the most self-reported clinical condition was hemorrhage, and the most self-reported intervention was hospital stay after delivery for more than one week. Cecatti et $\mathrm{al}^{21}$ also found hemorrhage as the most frequent clinical condition. Considering hypertensive diseases, including eclampsia and preeclampsia, our study found $8.4 \%$ of pregnancies with complications due to these causes. In contrast to our results, other studies that performed hospital audits have identified hypertensive diseases as the main causes of maternal morbidity. ${ }^{22,23}$ The explanation for this difference may be in the characteristic of the present study, which used self-reported morbidity.

Regarding race (skin color), even with its loss of significance in the multiple analyses probably due to the fact that it is a proxy of socioeconomic status, its importance to the study of maternal health cannot be ruled out. Maternal morbidity affects mainly women from racial minorities, so much so that the analysis of the association between maternal morbidity and racial characteristics has been proposed as 
592 Prevalence of Maternal Morbidity and Its Association with Socioeconomic Factors Rosendo et al.

Table 3 Bivariate analysis between the number of maternal complications and the variables related to socioeconomic status, demographic characteristics and maternal assistance. Natal (RN), Brazil, 2014

\begin{tabular}{|c|c|c|c|c|c|c|}
\hline \multirow[b]{2}{*}{ Variable } & \multicolumn{6}{|c|}{ Number of maternal complications } \\
\hline & $\mathrm{n}$ & Mean & SD & PR & $95 \% \mathrm{Cl}$ & $p$ \\
\hline \multicolumn{7}{|c|}{ Socioeconomic and demographic characteristics } \\
\hline \multicolumn{7}{|l|}{ Age } \\
\hline$\leq 34$ years old & 131 & 2.70 & 1.49 & 1 & & \\
\hline$\geq 35$ years old & 42 & 2.50 & 1.33 & 0.93 & $0.77-1.11$ & 0.409 \\
\hline Total & 173 & 2.65 & 1.45 & & & \\
\hline \multicolumn{7}{|l|}{ Race (skin color) } \\
\hline White & 62 & 2.32 & 1.25 & 1 & & \\
\hline Non-white & 103 & 2.86 & 1.49 & 1.23 & $1.04-1.46$ & 0.014 \\
\hline Total & 165 & 2.66 & 1.42 & & & \\
\hline \multicolumn{7}{|l|}{ Marital status } \\
\hline Married/stable relationship & 113 & 2.58 & 1.50 & 1 & & \\
\hline Single/divorced & 52 & 2.88 & 1.37 & 1.12 & $0.95-1.32$ & 0.181 \\
\hline Total & 165 & 2.67 & 1.46 & & & \\
\hline \multicolumn{7}{|l|}{ House crowding } \\
\hline$\leq 2$ dwellers per room & 104 & 2.51 & 1.43 & 1 & & \\
\hline$\geq 3$ dwellers per room & 67 & 2.90 & 1.46 & 1.15 & $0.98-1.36$ & 0.084 \\
\hline Total & 171 & 2.66 & 1.45 & & & \\
\hline \multicolumn{7}{|l|}{ Occupation } \\
\hline Employed & 76 & 2.78 & 1.48 & 1 & & \\
\hline Unemployed & 98 & 2.57 & 1.42 & 0.93 & $0.79-1.09$ & 0.352 \\
\hline Total & 174 & 2.66 & 1.45 & & & \\
\hline \multicolumn{7}{|l|}{ Socioeconomic status } \\
\hline High & 72 & 2.32 & 1.24 & 1 & & \\
\hline Low & 71 & 3.08 & 1.57 & 1.33 & $1.12-1.58$ & 0.001 \\
\hline Total & 143 & 2.70 & 1.46 & & & \\
\hline \multicolumn{7}{|l|}{ Maternal assistance } \\
\hline \multicolumn{7}{|l|}{ Prenatal care } \\
\hline Yes & 164 & 2.70 & 1.46 & 1 & & \\
\hline No & 10 & 2.10 & 1.20 & 0.78 & $0.55-1.10$ & 0.157 \\
\hline Total & 174 & 2.66 & 1.45 & & & \\
\hline \multicolumn{7}{|c|}{ Number of prenatal appointments } \\
\hline$\geq 6$ appointments & 127 & 2.68 & 1.53 & 1 & & \\
\hline$\leq 5$ appointments & 24 & 3.00 & 1.25 & 1.12 & $0.93-1.36$ & 0.242 \\
\hline Total & 151 & 2.73 & 1.49 & & & \\
\hline \multicolumn{7}{|c|}{ Time of 1st prenatal appointment } \\
\hline Up to the 3rd month & 139 & 2.65 & 1.49 & 1 & & \\
\hline From the 4th month & 21 & 3.05 & 1.20 & 1.15 & $0.95-1.39$ & 0.145 \\
\hline Total & 160 & 2.70 & 1.46 & & & \\
\hline \multicolumn{7}{|c|}{ Type of health service where prenatal care was performed } \\
\hline Private & 49 & 2.08 & 1.30 & 1 & & \\
\hline Public & 113 & 2.95 & 1.44 & 1.42 & $1.16-1.72$ & $<0.001$ \\
\hline Total & 162 & 2.69 & 1.46 & & & \\
\hline \multicolumn{7}{|c|}{ Basic exams recommended the by Ministry of Health } \\
\hline Performed all exams & 146 & 2.74 & 1.50 & 1 & & \\
\hline Did not perform all exams & 13 & 2.15 & 0.90 & 0.79 & $0.62-0.99$ & 0.045 \\
\hline Total & 159 & 2.69 & 1.47 & & & \\
\hline
\end{tabular}


Table 3 (Continued)

\begin{tabular}{|c|c|c|c|c|c|c|}
\hline & \multicolumn{6}{|c|}{ Number of maternal complications } \\
\hline \multicolumn{7}{|c|}{ Instructions about where the delivery would be performed } \\
\hline Yes & 101 & 2.47 & 1.34 & 1 & & \\
\hline No & 63 & 3.06 & 1.57 & 1.24 & $1.05-1.46$ & 0.010 \\
\hline Total & 164 & 2.70 & 1.46 & & & \\
\hline \multicolumn{7}{|c|}{ Delivery performed in the same place where the patient was instructed to go } \\
\hline Yes & 86 & 2.47 & 1.38 & 1 & & \\
\hline No & 15 & 2.47 & 1.12 & 1.00 & $0.778-1.28$ & 0.996 \\
\hline Total & 101 & 2.47 & 1.34 & & & \\
\hline \multicolumn{7}{|c|}{ Type of health service where the delivery was performed } \\
\hline Private & 35 & 1.80 & 1.13 & 1 & & \\
\hline Public & 125 & 2.93 & 1.43 & 1.63 & $1.30-2.03$ & $<0.001$ \\
\hline Total & 160 & 2.68 & 1.44 & & & \\
\hline \multicolumn{7}{|c|}{ Delivery performed in the first hospital } \\
\hline Yes & 135 & 2.54 & 1.43 & 1 & & \\
\hline No & 38 & 3.11 & 1.45 & 1.22 & $1.03-1.45$ & 0.024 \\
\hline Total & 173 & 2.66 & 1.45 & & & \\
\hline \multicolumn{7}{|c|}{ Type of delivery } \\
\hline Normal & 52 & 2.92 & 1.53 & 1 & & \\
\hline Cesarean & 111 & 2.57 & 1.41 & 0.88 & $0.74-1.05$ & 0.143 \\
\hline Total & 163 & 2.68 & 1.45 & & & \\
\hline \multicolumn{7}{|c|}{ Companion before the delivery } \\
\hline Yes & 149 & 2.60 & 1.42 & 1 & & \\
\hline No & 21 & 3.05 & 1.66 & 1.17 & $0.92-1.50$ & 0.198 \\
\hline Total & 170 & 2.65 & 1.45 & & & \\
\hline \multicolumn{7}{|c|}{ Companion during the delivery } \\
\hline Yes & 82 & 2.38 & 1.40 & 1 & & \\
\hline No & 78 & 2.83 & 1.38 & 1.19 & $1.01-1.41$ & 0.039 \\
\hline Total & 160 & 2.60 & 1.41 & & & \\
\hline \multicolumn{7}{|c|}{ Companion after the delivery } \\
\hline Yes & 136 & 2.54 & 1.43 & 1 & & \\
\hline No & 28 & 2.89 & 1.42 & 1.14 & $0.93-1.39$ & 0.213 \\
\hline Total & 164 & 2.60 & 1.43 & & & \\
\hline \multicolumn{7}{|c|}{ Companion full time } \\
\hline Yes & 76 & 2.28 & 1.31 & 1 & & \\
\hline No & 80 & 2.84 & 1.44 & 1.25 & $1.05-1.48$ & 0.011 \\
\hline Total & 156 & 2.56 & 1.40 & & & \\
\hline \multicolumn{7}{|c|}{ Days of hospitalization } \\
\hline$\leq 7$ days & 137 & 2.39 & 1.30 & 1 & & \\
\hline$\geq 7$ days & 35 & 3.80 & 1.49 & 1.59 & $1.36-1.86$ & $<0.001$ \\
\hline Total & 172 & 2.67 & 1.45 & & & \\
\hline
\end{tabular}

Abbreviations: $95 \% \mathrm{Cl}$, 95\% confidence interval; PR, prevalence ratio; SD, standard deviation.

Note: $p$ value obtained using the Wald Test.

a major means to assess health inequalities. In addition, other studies have shown higher prevalence rates of complications among black or indigenous women. ${ }^{21,24,25}$

In relation to the effect of the socioeconomic condition, it is important to point out that the SES variable came from a factor analysis, and represents the combined effects of income, education and possessions. These variables have been associ- ated to the prevalence of severe maternal outcomes in other studies. $^{26,27}$ Souza et al $^{13}$ found formal education as a factor associated to the prevalence of complications. Souza et $\mathrm{al}^{11}$ also found a higher prevalence of complications in regions with a lower human development index (HDI), and concluded that the differences in the occurrence of maternal morbidity are more likely a consequence of the relationship between the 
Table 4 Adjusted final model from Poisson regression analysis for the association among the number of maternal complications and demographic characteristics, socioeconomic status and maternal assistance. Natal (RN), Brazil, 2014

\begin{tabular}{|c|c|c|c|c|}
\hline \multirow[b]{3}{*}{ Condition } & \multicolumn{4}{|c|}{ Number of maternal complications } \\
\hline & \multicolumn{2}{|l|}{ Non-Adjusted } & \multicolumn{2}{|l|}{ Adjusted } \\
\hline & PR $(95 \% \mathrm{Cl})$ & $p$ & PR $(95 \% \mathrm{Cl})$ & $p$ \\
\hline Age & $0.93(0.77-1.11)$ & 0.409 & $1.03(0.87-1.23)$ & 0.713 \\
\hline Race (non-white) & $1.23(1.04-1.46)$ & 0.014 & $1.19(0.99-1.44)$ & 0.054 \\
\hline Low socioeconomic status & $1.33(1.12-1.58)$ & 0.001 & $1.23(1.03-1.46)$ & 0.019 \\
\hline Delivery performed in public service & $1.63(1.30-2.03)$ & $<0.001$ & $1.51(1.21-1.87)$ & $<0.001$ \\
\hline
\end{tabular}

Abbreviations: $95 \% \mathrm{Cl}$, 95\% confidence interval; PR, prevalence ratio.

social determinants of human development and the maternal health conditions.

Regarding the demographic characteristics, age is another important aspect that must be mentioned. The extremes of the reproductive age must be looked at with attention, as each one of them presents specific conditions. Pregnancy in adolescence mostly occurs as an undesirable outcome, which increases the risk of unsafe abortions, associated to the fact that there is less adherence to prenatal care in this age group. ${ }^{28}$ On the other hand, older women are also considered as having a higher risk of obstetric complications due to their higher prevalence rate of co-morbidities and/or multiple births. $^{29}$ Several studies have reported that complications in pregnancy increase as age does, especially in women aged 35 years and older. ${ }^{13,30-32}$ A similar result was not found in the present study.

In relation to the type of healthcare service where the delivery occurred, we found higher prevalence rates among those women who received care in public health services. However, it is important to highlight that this association does not necessarily mean a causal relationship. Amaral et $\mathrm{al}^{22}$ performed a population-based study on private and public services in the city of Campinas, in the state of São Paulo, in the Southeast region of Brazil. They found that all cases of severe maternal morbidity, as well as maternal death, occurred in the public hospital of that municipality. Adisasmita et $\mathrm{al}^{33}$ also collected data from medical records, and reported that the occurrence of maternal morbidity was much higher in public hospitals than in private ones. In addition, the health conditions of the hospitalized patients in the public hospital were considerably more severe, suggesting that there has been a delay in the referral of assistance. This fact can be explained by the fact that the public health services usually concentrate on all referral hospitals, where a great part of the most complicated cases are referred to. In this case, they naturally present a higher probability of occurrence of the most severe outcomes. On the other hand, it is also possible to admit that women's assistance in public healthcare services has really low-quality, especially in lowincome regions. ${ }^{21}$

Although "service where the delivery occurred" was the only variable to maintain a significant association in the multiple analyses, other important aspects of women's healthcare showed significant association in the non-adjusted analysis, such as: a) high prevalence of maternal complications were associated to prenatal care in public services, meaning a weakness in maternal assistance in primary care; b) association to the lack of a companion during delivery was also found, which could mean a lack of humanization in assistance; and c) higher prevalence was associated to the "absence of instructions about where the delivery would occur" and to "delivery not performed in the first hospital," meaning problems in the integration between primary and tertiary assistance. Such findings have important implications for public health, as they stress the necessity to implement a surveillance system that is able to impact the health-disease process to avoid the most tragic maternalrelated outcomes.

Therefore, healthcare services should implement evidence-based clinical protocols that should be incorporated to assist daily practices. ${ }^{22}$ The major challenge is to consolidate these practices in all complexity levels, be it in public or private services, in such a manner that this cannot be conducted only through the professional's motivation and/ or through focalized and non-integrated projects. This approach will only happen if maternal healthcare is based on public policies that promote the integration of health services, strengthening health assistance at all levels, and involving several participants in this process, including the patients, in this case, the women.

The present study has some strengths and limitations. The main limitation is the use of self-reported information, which is influenced by socioeconomic characteristics, and has a possibility of information bias. Besides, since we used the amount of pregnancies as the denominator instead of the number of childbirths, this can difficult the comparison of our results with those of other studies. Regarding the generalization of the results (external validity), although their representativeness is restricted to the city of Natal, in the Northeast region of Brazil, it is possible to extrapolate the results to other contexts, like cities with similar characteristics and that present health inequalities. In addition, this study is a population-based survey, which brings forth important information usually not available in the health information systems. Such information contributes to make fundamental questions about maternal health clearer. 


\section{Conclusion}

Our study showed that women in a worse socioeconomic situation had higher prevalence of maternal morbidity. Additionally, the women who delivered in public services had higher prevalence of maternal morbidity, which could indicate that public health care usually deals with the more complex cases. The association between socioeconomic factors and the prevalence of maternal complications reinforces the urgency of strengthening public policies that reduce health inequalities through actions focusing on these determinants. Healthcare services can play an important role as attenuators of these inequalities.

\section{Funding}

The present study was funded by Conselho Nacional de Desenvolvimento Científico e Tecnológico (CNPq), under process number 477496/2011-3

\section{Conflict of Interests}

Authors declare no conflict of interest.

\section{References}

1 World Health Organization. Commission on Social Determinants of Health. Closing the gap in a generation: health equity through action on the social determinants of health. Geneva: WHO; 2008

2 de Graaf JP, Steegers EA, Bonsel GJ. Inequalities in perinatal and maternal health. Curr Opin Obstet Gynecol 2013;25(02):98-108

3 United Nations. [Internet]. The Millennium Development Goals Report 2013. New York: United Nations; 2013 [cited 2014 May 25]. Avaliable from: http://www.un.org/millenniumgoals/ pdf/report-2013/mdg-report-2013-english.pdf

4 Saucedo M, Deneux-Tharaux C, Bouvier-Colle MH. Understanding regional differences in maternal mortality: a national case-control study in France. BJOG 2012;119(05):573-581

5 World Health Organization. Evaluating the quality care for severe pregnancy complications: the WHO near-miss approach for maternal health. Geneva: WHO; 2011

6 Cecatti JG, Parpinelli MA. Maternal health in Brazil: priorities and challenges. Cad Saude Publica 2011;27(07):1256

7 Souza JP. [Maternal mortality and development: the obstetric transition in Brazil]. Rev Bras Ginecol Obstet 2013;35(12):533-535

8 Mantel GD, Buchmann E, Rees H, Pattinson RC. Severe acute maternal morbidity: a pilot study of a definition for a nearmiss. Br J Obstet Gynaecol 1998;105(09):985-990

9 Waterstone M, Bewley S, Wolfe C. Incidence and predictors of severe obstetric morbidity: case-control study. BMJ 2001;322 (7294):1089-1093, discussion 1093-1094

10 Souza JP, Cecatti JG, Parpinelli MA, Serruya SJ, Amaral E. Appropriate criteria for identification of near-miss maternal morbidity in tertiary care facilities: a cross sectional study. BMC Pregnancy Childbirth 2007;7:20

11 Souza JP, Sousa MH, Parpinelli MA, Amaral E, Cecatti JG. Selfreported maternal morbidity and associated factors among Brazilian women. Rev Assoc Med Bras (1992) 2008;54(03): 249-255

12 Souza JP, Parpinelli MA, Amaral E, Cecatti JG. Population surveys using validated questionnaires provided useful information on the prevalence of maternal morbidities. J Clin Epidemiol 2008; 61(02):169-176
13 Souza JP, Cecatti JG, Parpinelli MA, et al. Maternal morbidity and near miss in the community: findings from the 2006 Brazilian demographic health survey. BJOG 2010;117(13):1586-1592

14 de Moraes AP, Barreto SM, Passos VMA, Golino PS, Costa JE, Vasconcelos MX. Severe maternal morbidity: a case-control study in Maranhao, Brazil. Reprod Health 2013;10:11

15 Souza JP, Cecatti JG, Pacagnella RC, et al. Development and validation of a questionnaire to identify severe maternal morbidity in epidemiological surveys. Reprod Health 2010;7:16

16 Torres M, Moayedi S. Gynecologic and other infections in pregnancy. Emerg Med Clin North Am 2012;30(04):869-884

17 Lwanga SK, Lemeshow S. Sample size determination in health studies: a practical manual. Geneva: WHO; 1991

18 World Health Organization. The EPI coverage survey. Geneva: WHO; 1991

19 United Nations Population Fund. Rich Mother, poor mother: the social determinants of maternal death. New York, UN2012

20 Souza JP, Parpinelli MA, Amaral E, Cecatti JG. [Obstetric care and severe pregnancy complications in Latin America and the Caribbean: an analysis of information from demographic health surveys]. Rev Panam Salud Publica 2007;21(06):396-401 Portuguese

21 Cecatti JG, Souza RT, Pacagnella RC, Leal MC, Moura EC, Santos LM. Maternal near miss among women using the public health system in the Amazon and Northeast regions of Brazil. Rev Panam Salud Publica 2015;37(4-5):232-238

22 Amaral E, Souza JP, Surita F, et al. A population-based surveillance study on severe acute maternal morbidity (near-miss) and adverse perinatal outcomes in Campinas, Brazil: the Vigimoma Project. BMC Pregnancy Childbirth 2011;11:9

23 Lotufo FA, Parpinelli MA, Haddad SM, Surita FG, Cecatti JG. Applying the new concept of maternal near-miss in an intensive care unit. Clinics (Sao Paulo) 2012;67(03):225-230

24 Brown HL, Small M, Taylor YJ, Chireau M, Howard DL. Near miss maternal mortality in a multiethnic population. Ann Epidemiol 2011;21(02):73-77

25 Creanga AA, Bateman BT, Kuklina EV, Callaghan WM. Racial and ethnic disparities in severe maternal morbidity: a multistate analysis, 2008-2010. Am J Obstet Gynecol 2014;210(05):435.e1-435.e8

26 Karlsen S, Say L, Souza JP, et al. The relationship between maternal education and mortality among women giving birth in health care institutions: analysis of the cross sectional WHO Global Survey on Maternal and Perinatal Health. BMC Public Health 2011;11:606

27 Tunçalp Ö, Souza JP, Hindin MJ, et al; WHO Multicountry Survey on Maternal and Newborn Health Research Network. Education and severe maternal outcomes in developing countries: a multicountry cross-sectional survey. BJOG 2014;121(Suppl 1):57-65

28 Ham P, Allen C. Adolescent health screening and counseling. Am Fam Physician 2012;86(12):1109-1116

29 Lamminpää R, Vehviläinen-Julkunen K, Gissler M, Heinonen S. Preeclampsia complicated by advanced maternal age: a registrybased study on primiparous women in Finland 1997-2008. BMC Pregnancy Childbirth 2012;12:47

30 Oliveira FC Jr, Costa ML, Cecatti JG, Pinto e Silva JL, Surita FG. Maternal morbidity and near miss associated with maternal age: the innovative approach of the 2006 Brazilian demographic health survey. Clinics (Sao Paulo) 2013;68(07):922-927

31 Oliveira FC Jr, Surita FG, Pinto E Silva JL, et al; Brazilian Network for Surveillance of Severe Maternal Morbidity Study Group. Severe maternal morbidity and maternal near miss in the extremes of reproductive age: results from a national cross- sectional multicenter study. BMC Pregnancy Childbirth 2014;14:77

32 Galvão LPL, Alvim-Pereira F, de Mendonça CM, et al. The prevalence of severe maternal morbidity and near miss and associated factors in Sergipe, Northeast Brazil. BMC Pregnancy Childbirth 2014;14:25

33 Adisasmita A, Deviany PE, Nandiaty F, Stanton C, Ronsmans C. Obstetric near miss and deaths in public and private hospitals in Indonesia. BMC Pregnancy Childbirth 2008;8:10 